\title{
Elimination of lymphatic filariasis: current perspectives on mass drug administration
}

This article was published in the following Dove Press journal: Research and Reports in Tropical Medicine

\section{John O Gyapong'}

Irene O Owusu ${ }^{2}$

Frances B da-Costa Vroom ${ }^{3}$

Ernest $O$ Mensah $^{4}$

Margaret Gyapong ${ }^{5}$

'Centre for Neglected Tropical

Diseases Research, Institute of Health Research, University of Health and

Allied Sciences, Ho, ${ }^{2}$ Department of Epidemiology, Noguchi Memorial Institute for Medical Research, ${ }^{3}$ Department of Biostatistics, School of Public Health, ${ }^{4}$ Department of Health Policy Planning and Management, School of Public Health, University of Ghana, Accra, ${ }^{5}$ Centre for Health Policy and Implementation Research, Institute of Health Research, University of Health and Allied Sciences, Ho, Ghana
Correspondence: John O Gyapong Centre for Neglected Tropical Diseases Research, Institute of Health Research, University of Health and Allied Sciences, PMB 3 I Ho, Volta Region, Ghana Email jgyapong@uhas.edu.gh

\begin{abstract}
Following the London declaration on neglected tropical diseases (NTDs) in 2012 and inspired by the WHO 2020 roadmap to control or eliminate NTDs, the Global Programme to Eliminate Lymphatic Filariasis (GPELF) intensified preventive chemotherapy and management of morbidity as the two main strategies to enhance progress towards the elimination of lymphatic filariasis (LF). This paper focuses on current perspectives of mass drug administration (MDA) towards the elimination of LF. The goal of MDA is to reduce the density of parasites circulating in the blood of infected persons and the intensity of infection in communities to levels where transmission is no longer sustainable by the mosquito vector. Three drugs, diethylcarbamazine, albendazole, and ivermectin are currently available for LF treatment, and their effectiveness and relative safety have opened the possibility of treating the entire population at risk. Currently, almost all LF endemic countries rely on the single-dose two-drug regimen recommended by the GPELF to achieve elimination. The 4th WHO report on NTDs has indicated that considerable progress has been made towards elimination of LF in some countries while acknowledging some challenges. In this review, we conclude that the 2020 elimination goal can be achieved if issues pertaining to the drug distribution, health system and implementation challenges are addressed. Keywords: mass drug administration, disease elimination, lymphatic filariasis, neglected tropical diseases, community health worker, treatment compliance
\end{abstract}

\section{Introduction}

Lymphatic filariasis (LF) is one of the six infectious diseases identified by the International Task Force for Disease Eradication as "eradicable" or "potentially eradicable". 1 LF has therefore been targeted for elimination by the WHO. In recognition of its eradicability, the Global Programme to Eliminate Lymphatic Filariasis (GPELF) was set up to ensure that the resolution passed by the World Health Assembly in 1997 (WHA 50.29 ) to eliminate LF by 2020 was achieved. ${ }^{2}$ To achieve the goal of elimination of LF as a public health problem, the GPELF identified two main strategies: preventive chemotherapy to interrupt transmission of LF and management of morbidity (lymphedema and hydrocele) associated with the disease. ${ }^{3}$ Of the two strategies, preventive chemotherapy delivered through mass drug administration (MDA) has gained prominence as interruption of transmission was prioritized in the first decade (2000-2009) of implementation of the GPELF.

To achieve interruption of parasite transmission, MDA must achieve a program coverage of at least $80 \%$ (of individuals at risk in an implementation unit: usually the district in which MDA is happening) over 5-6 years of annual treatment or longer in 
areas with high baseline microfilaria (mf) prevalence. ${ }^{4,5}$ The goal of MDA is to reduce the density of parasites circulating in the blood of infected persons and prevalence of infection in communities to levels where transmission is no longer sustainable by the mosquito vector. ${ }^{6}$ During MDA, one of the three combinations of antihelminthic medicines is administered: albendazole (ALB) $(400 \mathrm{mg})+$ diethylcarbamazine (DEC) citrate $(6 \mathrm{mg} / \mathrm{kg})$; ALB (400 mg) + ivermectin (IVM) $(150-200 \mu \mathrm{g} / \mathrm{kg})$ in areas co-endemic for onchocerciasis; or ALB (400 mg) preferably twice yearly in areas co-endemic for loiasis ${ }^{7-9}$ to all persons at risk of the disease living in endemic areas.

\section{Scientific basis of the MDA program}

In the 1980s, prior to the use of the combination of antihelminthic drugs, LF diagnosis mainly relied on microscopic identification of $\mathrm{mfs}$ in blood specimens. Treatment was by the administration of DEC for between 12 and 14 days. This treatment was focused on the infected individual. ${ }^{10}$ Infection was not cured completely but was able to decrease mf levels markedly. ${ }^{11}$ As diagnosis advanced and more complex tools were developed, IVM and ALB were identified as LF - active drugs. Three drugs are therefore currently available for LF treatment: DEC, ALB and IVM. A combination of any two of these drugs have been found to be more efficacious in microfilaria clearance than when they are administered as monotherapy. ${ }^{12}$ The effectiveness of these three-drug combinations opened up the possibility of treating the entire population at risk since the absence of $\mathrm{mf}$ in the blood is essential to achieve LF elimination. ${ }^{6}$

Over the years, the availability of new and simplified diagnostic tools and equally effective single-dose and multidrug treatment regimens has brought about the shift from the focus on infected individuals to infection prevention in communities affected and those at risk. Based on the estimated reproductive lifespan of the adult worm and the efficacy of the drugs available, between four and six rounds of MDA were anticipated to be enough to reduce $\mathrm{mf}$ to levels where active transmission can no longer occur. ${ }^{13}$ Currently, almost all LF endemic countries rely on the single-dose two-drug regimen recommended by the GPELF to achieve elimination. Multiple-drug therapy has been recognized as the most effective way to treat various diseases. This enhances drug efficacy and minimizes the likelihood of the development of resistance among the target population. ${ }^{6}$

Pharmacokinetic studies on the single-dose two-regimen drugs have shown that all three drugs whether administered singly or co-administered were well tolerated by the human body and safe in both microfilaraemic and non-microfilaraemic individuals..$^{14,15}$ Studies to determine the efficacy of these drugs showed that a combination of ALB + DEC, ALB + IVM and DEC + IVM showed dramatic falls in $\mathrm{mf}$ levels for long periods when administered in repeated annual MDAs. ${ }^{16}$ The combination of DEC + IVM was also found to be safe to use outside of onchocerciasis and loiasis endemic areas. ${ }^{17}$ Testing the two-drug versus one-drug regime showed that in all cases, addition of ALB decreased mf density in affected individuals or totally cleared $\mathrm{mf} .{ }^{6}$ Micro-simulation models that show the effect of MDA on LF elimination have demonstrated that the number of MDA rounds necessary to achieve elimination depends on drug coverage, drug efficacy and endemicity level of the area. ${ }^{18,19}$

In China, distribution of DEC-fortified salt to the entire population at risk of the disease for between 1 and 2 years brought about elimination of the disease. Administration over a period of 18 days to 1 year has been shown to be effective in elimination efforts. ${ }^{20}$ As a result, China adopted DECfortified salt as a strategy for LF elimination, and Chinese researchers demonstrated its feasibility, effectiveness and safety, as well as the low frequency of adverse reactions. Salt, containing a $0.3 \%$ concentration of DEC was used for MDA and continued for 3-6 months. The advantage of this approach was that side effects were kept to a minimum and compliance was therefore never a problem. The main approach, however, was to screen for $\mathrm{mf}$, and to follow this up with 3- to 7-day courses of DEC tablets at $4.2 \mathrm{~g} / \mathrm{kg}$ (sic) body weight, with at least a 1-month interval between each course. ${ }^{21}$

Studies have also shown that endosymbiont rickettsiae found in onchocerciasis and LF parasites have an intimate relationship with the growth and reproduction of filarial parasites. Treatment of rickettsial infections with doxycycline has been shown to have profound effect on both $\mathrm{mf}$ and adult worms in patients with onchocerciasis and LF. ${ }^{21}$ Clinical trials in Ghana showed that long-term treatment with doxycycline (6 weeks of treatment) in patients with Wuchereria bancrofti infection resulted in 96\% loss of Wolbachia and $99 \%$ reduction in $W$. bancrofti $\mathrm{mfs} .^{22}$ This treatment option is yet to be operationalized due to the challenges associated with widespread use of antibiotics in MDA.

\section{Programmatic coverage and impact of MDA}

The strategic decision to move from treatment of infected individuals to treatment of entire communities at risk has had a profound effect on the quest to eliminate LF as a public health 
problem. After 13 years of program implementation of the GPELF (2000-2012), a cumulative total of 6.37 billion treatments have been delivered to more than 820 million people in 63 endemic countries at least once, out of which 4.45 million have been consumed by population in endemic areas. Since the inception of the GPELF, approximately 97 million cases of LF have been prevented or cured. This includes 79.20 million mf carriers, 18.73 million hydrocoele cases and 5.49 million lymphoedema cases. Also, 10.98 million and 1.17 million cases of microfilaraemia and lymphoedema due to Brugia species have been prevented or cured by the GPELF's efforts. Also, 10.98 million and 1.17 million cases of microfilaraemia and lymphedema due to Brugia species have been prevented. ${ }^{23}$ The estimated fall in LF prevalence was 59\%, that is, from 3.55\% to $1.47 \%$. The highest fall in prevalence is for microfilaraemia, $68 \%$, followed by hydrocele, $49 \%$, and lymphedema, $25 \%$ (Table 1). After 13 years of MDA, there was still the high figure of 36.45 million $\mathrm{mf}$ cases, but this would have been an astounding 115.65 million cases in the absence of the GPELF's MDA program. This means the progression of LF to chronic disease has been averted in 79.20 million people. ${ }^{23}$

Episodes of adenolymphangitis (ADL) are a problem in-LF affected communities with their incidence being higher in persons affected by chronic disease conditions. The number of cases of ADL averted by MDA is estimated to be about 38.85 million per annum. As of 2015, 18 LF endemic countries globally had reduced infection prevalence to levels at which transmission is assumed to be unsustainable. Six of these countries have now been acknowledged as achieving the elimination of LF as a public health problem. Many more countries are at different stages of implementing MDA. If effective coverage can be achieved in some 20 countries that have implemented at least one round of MDA in all implementation units, they may be able to stop MDA by $2020 .{ }^{9}$

More than $\$ 100$ billion in economic losses have been averted due to the success of the MDA. ${ }^{9}$ In 2015, national LF programs targeted 698.3 million people for treatment during MDA; however, data reported to WHO showed that by September 2015, 556.2 million people were treated for program coverage of $79.6 \%$. Coverage of the total population requiring MDA was $58.8 \%$ and therefore the 2015 coverage was a great improvement and a big success. ${ }^{9}$ The impact of MDA on antigenemia has also been profound. In American Samoa, antigen levels have fallen because of MDA with DEC and ALB after five annual rounds of treatment. Reduction in antigen levels occurred between 2003 and 2006 from $13.5 \%$ to $0.95 \%$. In Papua New Guinea, MDA was seen to have dramatic effects on all filariasis parameters and decreased incidence rates of the disease. ${ }^{24}$ A study on the impact of six annual rounds of MDA using $\mathrm{DEC}$ and ALB in Indonesia showed that $\mathrm{mf}$ rates dropped quickly to below $1 \%$ and remained so for 34 months after the end of the study. The prevalence of filarial-specific IgG4 antibodies measured by the Brugia Rapid test was also about $80 \%$ before MDA but dropped to about $6 \%$ at the end of the study period. ${ }^{25}$ Such dramatic declines in antigen prevalence validates the effectiveness of MDA as a public health strategy. ${ }^{26}$

Table I Estimated number of different categories of LF cases prevented by the MDA program under GPELF and burden as of 2013

\begin{tabular}{|c|c|c|c|c|c|}
\hline Clinical Category & $\begin{array}{l}\text { LF burden } \\
(2000)\end{array}$ & $\begin{array}{l}\text { Estimated } \\
\text { burden }(20 \mid 3) \\
\text { assuming no } \\
\text { MDA in place }\end{array}$ & $\begin{array}{l}\text { Cases } \\
\text { prevented or } \\
\text { cured by MDA }\end{array}$ & $\begin{array}{l}\text { Current burden } \\
(2013)\end{array}$ & $\begin{array}{l}\text { \% Reduction in } \\
\text { burden }\end{array}$ \\
\hline \multicolumn{6}{|l|}{ W. bancrofti } \\
\hline Microfilaraemia & 80.46 & 102.46 & 68.22 & 34.25 & 67 \\
\hline Hydrocele & 29.94 & 38.16 & 18.73 & 19.43 & 49 \\
\hline Lymphedema & 14.84 & 18.72 & 4.32 & $|4.4|$ & 23 \\
\hline Total & 117.24 & 149.16 & 85.43 & 63.73 & 57 \\
\hline \multicolumn{6}{|l|}{ B. malayi } \\
\hline Microfilaraemia & 10.67 & 13.19 & 10.98 & 2.2 & 83 \\
\hline Lymphedema & 2.82 & 3.44 & 1.17 & 2.27 & 34 \\
\hline Total & 12.58 & 15.42 & 11.28 & 4.15 & 73 \\
\hline \multicolumn{6}{|c|}{ W. bancrofti + B. malayi } \\
\hline Microfilaraemia & 91.13 & 115.65 & 79.2 & 36.45 & 68 \\
\hline Hydrocele & 29.94 & 38.16 & 18.73 & 19.43 & 49 \\
\hline Lymphedema & 17.66 & 22.16 & 5.49 & 16.68 & 25 \\
\hline Total & 129.82 & 164.58 & 96.71 & 67.88 & 59 \\
\hline
\end{tabular}

Notes: All figures, except \% reduction, in millions. Adapted from Ramaiah KD, Ottesen EA. Progress and impact of I3 years of the global programme to eliminate lymphatic filariasis on reducing the burden of filarial disease. PLoS Negl Trop Dis. 2014;8(I I):e33 I9. ${ }^{23}$

Abbreviations: B. malayi, Brugia malayi; GPELF, Global Programme to Eliminate Lymphatic Filariasis; LF, lymphatic filariasis; MDA, mass drug administration; W. bancrofti, Wuchereria bancrofti 
India contributes nearly one-third of the global burden of LF. A successful MDA program in India is therefore likely to heavily impact the global program. After eight rounds of MDA, assessment of the epidemiological situation showed that mf prevalence was $0.2 \%$, while antigenemia prevalence in children born during MDA was $0.8 \%$, well below the $1 \%$ antigenemia level required for stopping MDA. However, a few areas were identified as having ongoing transmission and spatial clustering of infection, which indicate the need for good surveillance strategies to detect these areas. ${ }^{27}$

MDA has not only been very instrumental in the alleviation of LF infection but also aided in reducing the intensity of soil transmitted helminth infections. The medicines used in MDA programs are effective in treating STH infections in co-endemic countries. Approximately 36.1 million preschoolaged children and 139.3 million school-aged children were treated during MDA for LF in 2015. All the children received ALB, while 52 million also received IVM. The treatment contributed significantly to reducing STH infections in the target groups and was beneficial to women of childbearing age and other adults. ${ }^{9}$ Studies have all shown that MDA for LF has contributed greatly to the decline of STH infections in school children..$^{25,28,29}$ The problem at hand is how to sustain the decline now that most countries have stopped MDA and are in the Transmission Assessment Survey phase.

\section{MDA and its role in a typical health system}

Since its inception, MDA has been conducted using vertical health system structures or integrated with general health systems of endemic countries. A combination of the two approaches or a partial integrated approach is often the case. ${ }^{30}$ MDAs are mainly conducted using community volunteers and health staff especially community health workers or community drug distributors (CDDs), but a combination of different groups of people is reported to be more effective at achieving high treatment coverage. ${ }^{31,32}$

Two main approaches are used in the conduct of MDA: house-to-house or static point medicines distribution. A combination of the two may be applied depending on the area of interest. In either case, directly observed therapy (DOT) is the preferred mode of administration of medicines. ${ }^{33-36}$ In the recent past, disease control and elimination programs were conducted as vertical programs. However, as progress is being made to achieve elimination, control and eradication goals, MDA for LF and other neglected tropical diseases (NTDs) are being conducted on an integrated delivery platform to meet the health needs and treat the affected population. ${ }^{37,38}$ Integrated MDA for LF, onchocerciasis, soil transmitted helminthiasis, schistosomiasis and trachoma has been conducted together or in many combinations on the same MDA campaign using the appropriate combination of DEC/IVM, ALB, praziquantel and azithromycin due to the good safety profile when used together. ${ }^{14,39}$

The health systems in developing countries where LF is most prevalent are designed primarily for routine service delivery rather than episodic mass campaigns such as MDAs and National Immunization Days. Unlike routine health care service delivery, LF MDA is an annual event with a limited execution period. It is organized as a campaign with a series of interlinked activities - planning, medicines supply chain management, training, social mobilization, drug administration and management of adverse events, data collection and reporting and coverage surveys (Figure 1). Despite the nonroutine nature of MDAs, it engages all components of the health system - service delivery, governance and leadership, financing, human resources, information, and medical products, vaccines and technologies. ${ }^{40}$ Therefore, a robust health system is required to deliver effective MDA that achieves effective and high coverage over the number of treatment rounds required to ensure interruption of transmission. The health system particularly must have the capacity to deliver interventions at the community level and in rural areas where access to health care is most challenged. ${ }^{41}$

Global health initiatives such as the GPELF may be an avenue to strengthen local health systems but the opposite may be the case where the host health system is weak, thus compelling the setting up of parallel structures to achieve the objectives of the program. ${ }^{42}$ Cost of MDA besides the value of donated drugs is attributable to contribution of country governments through the use of health human resource, health facilities, transport, supply chain system, health information management system, training facilities, etc. ${ }^{43} \mathrm{~A}$ weak health system, therefore, implies that these costs must be borne by the LF programs, significantly increasing the cost of MDA, which may be prohibitive to both partners and governments of endemic countries. MDA whether implemented through vertical or integrated delivery platforms requires fairly robust health systems to ensure proper identification and selection of drug distributors with the community, train and re-train front line workers, and supervise appropriately to be successful.

A key component of MDAs is the donated medicine, which is the largest component of MDA cost. The absence of 


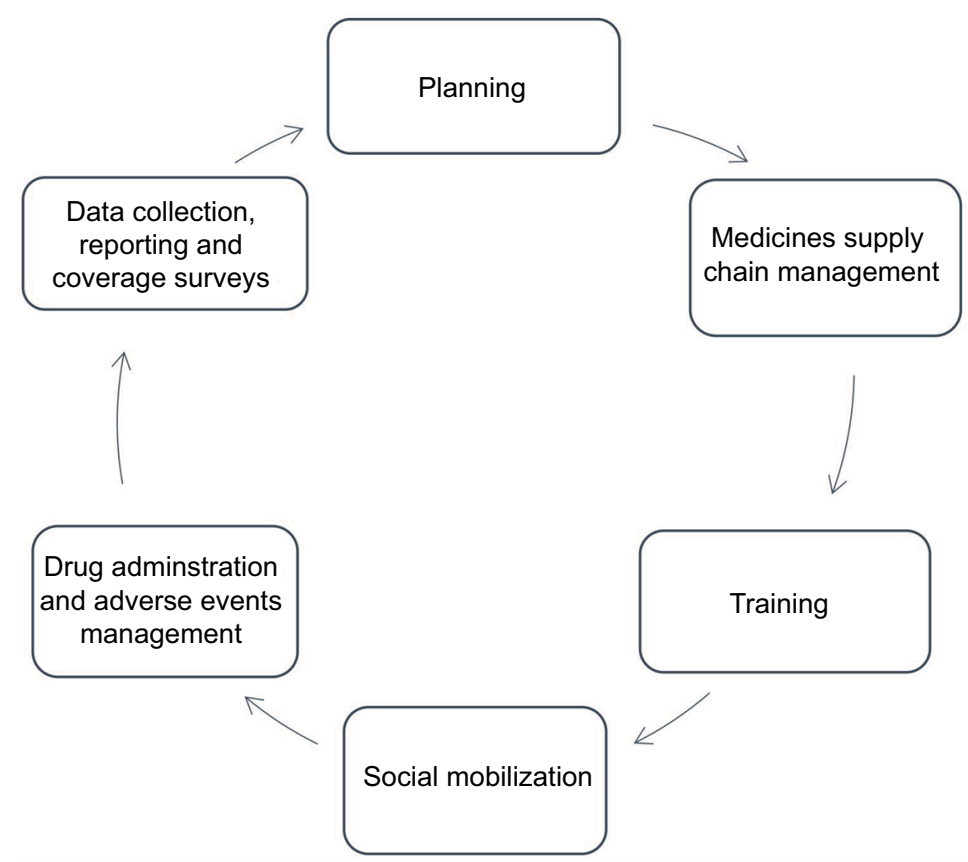

Figure I MDA activity cycle.

Abbreviation: MDA, mass drug administration.

safe Central Medical Stores as well as a network of Regional and District Medical stores to hold stocks close to endemic communities prior to MDA will threaten the success of the preventive chemotherapy intervention, thus compromising the efficacy of the medicines. A weak supply chain management system may result in wastage of (through maldistribution, expiry and poor reverse logistics) large quantities of medicines, a situation that may threaten sustainability of the donation program. Use of private storage and distribution system due to weak health system will be additional cost to the MDA, as MDA depends on existing health system structures at the sub-national levels. A weak health system means that formal health system structures may be too far away from endemic communities. It also means that there will be little or no opportunity to integrate LF MDA with other interventions such as bed net distribution. Also, human resource needs for MDAs will include significant numbers of other cadres of staff besides CDDs. Where expertise has to be imported, cost escalation will be the result.

\section{MDA implementation challenges}

In the implementation of the GPELF's effort to eliminate LF, there have been challenges. These may have arisen as a result of challenges in the health system or the endemic communities. Some areas where challenges have been identified are discussed here.

\section{Reporting}

The first implementation challenge recognized in the LF elimination program is data reporting. Data reported for LF programs are treatment coverage, which is generated from the community level by health volunteers, coverage surveys and case identification reports for clinical follow-up of conditions such as hydrocele and elephantiasis. Treatment data are recorded at household level by community health volunteers (CHVs), summarized at community level and submitted to the various supervising units. ${ }^{37,44}$ This cascading reporting lends itself to late reporting at the sub-district and district levels due to other competing health programs and the arduous task of data validation that needs to occur to ensure data accuracy. ${ }^{45}$ Other factors such as poor road networks in endemic populations, inadequate transport resources for supervisory teams and remoteness of some communities are also known to affect timeliness of reporting. ${ }^{46}$ This becomes even harder when MDAs are conducted during the rainy season in these poor remote areas.

Data reported over the years have also revealed data inaccuracy. ${ }^{37,45}$ Having $100 \%$ geographic coverage, which basically involves conducting MDA in all the endemic communities, is usually achieved in most countries. Reported treatment coverage of $>65 \%$ has sometimes been questioned in some countries. This is not necessarily an LF program challenge, but has been found to be characteristic of disease 
control programs. ${ }^{47-49}$ Overestimation and underestimation of treatment coverage have been reported in a number of studies. A study found that over $60 \%$ of data reported in three endemic districts in Ghana were inaccurate. ${ }^{50}$ Other errors have also been attributed to inaccurate denominator (population census data or program data) used in estimating treatment drug coverage. ${ }^{47}$ In India as well, published drug coverage estimates are characterized as estimates of drug distribution. This leads to overestimation of actual drug consumption or compliance to MDA. This is because the DOT approach is not always used. Thus, some people may receive the drugs but may not necessarily swallow them..$^{51,52}$ Using the census data becomes a challenge when it is not updated or is too old. A description of a situation in Papua, Indonesia, where three different population figures were provided by village authorities, the village health worker and a village elder resulted in different treatment coverage being estimated for the same community. ${ }^{53} \mathrm{~A}$ study in Mali preregistered community members in order to avoid this challenge. ${ }^{37}$ Coverage surveys are usually undertaken in order to validate the drug coverage reported. The coverage surveys are conducted at household levels and allow other dimensions such as sex inequities, access by different age groups and effectiveness of social mobilization to be monitored. ${ }^{47}$ Such a survey determined that $73 \%$ of treatment coverage estimates were over-reported. ${ }^{54}$

For most countries, LF treatment data and NTD data as a whole are not included in health indicators reported at the national level. For example in Ghana, the District Health Management Information System does not capture indicators on LF. This is partly because these programs are usually managed vertically and are donor funded; so, reporting is donor focused rather than country need focused. Reporting needs should be realigned with country needs in order to have the endemic countries more interested in the elimination of LF by the WHO target of 2020 .

\section{Incentives}

Motivation of health workers and community volunteers has been identified as a challenge in most developing countries. ${ }^{55}$ These have been classified as extrinsic motivators and intrinsic motivators. ${ }^{56}$ Intrinsic motivators have been defined as the innate values such as altruism and pride, while the extrinsic motivators are gained from external rewards, which include money or opportunities for employment. ${ }^{57}$ Community health workers for NTD programs are engaged as volunteers, expected to give their time to bridge the gap between the remote communities and the health system. ${ }^{58}$ Though engaged as volunteers, some incentives have to be provided to keep them motivated to distribute the donated drugs in their communities. ${ }^{59}$

The role of incentives in LF MDAs cannot be overemphasized. Community health volunteers are usually given transportation allowance when they travel for training or attend annual MDA review meetings. They also receive an allowance for drug distribution when MDA is concluded. These incentives have been deemed woefully inadequate since CHVs usually leave their jobs or other income earning activities to perform these tasks. ${ }^{34}$ It has become increasingly challenging to retain CHVs for NTD programs due to low financial incentives. ${ }^{60}$ Studies have shown that incentives provided in other health programs negatively impact that given to $\mathrm{CHVs}$ in NTD programs. ${ }^{34}$ For example, a study showed that CDDs felt less motivated to participate in NTD programs compared to other health programs because more financial incentives were provided and the other programs required less effort. ${ }^{34}$ Communities, in some cases, agreed the CHVs would need incentives and agreed to consider appropriate incentives for them. ${ }^{61}$ Local government in Mali set an example by providing funds to motivate CHVs. ${ }^{37}$ Incentives for CHVs in various forms have been shown to enhance program delivery and community participation. ${ }^{44,61,62}$

CHVs have also been known to request for other nonmonetary incentives such as t-shirts and ID cards to make them recognizable in the community during the campaigns, preferential care when attending clinic, raincoats and boots to help them navigate the communities during the rainy season and many more..$^{57,59}$ These have not been adequately addressed and resulted in waning interest in the LF MDAs, sometimes leading to high attrition or turnover among the drug distributors. ${ }^{63}$ There have also been discussions on possibilities of paying them monthly allowances and engaging them as volunteers for all health programs within their communities. ${ }^{57}$ These are hoped to serve as motivators and garner more interest in the MDAs. However, there are arguments against such advances due to potential lack of sustainability. ${ }^{45,57}$ Incentives during MDAs appear not to be only related to CHVs but also to community members. This is expected to improve their trust in the health teams, since majority of persons in communities may not show visible signs of the disease and will be hesitant to take the drugs. Provision of bed nets to community members have also been suggested as a way of incentivizing them to take the drugs..$^{53}$ 


\section{Community participation}

Community participation has been found to be one of the major challenges to the success of the MDA program. A lack of community participation hampers program implementation of all drug administration programs rather than only MDA for LF. The nature of LF infection necessitates that whole communities have to be treated to ensure that $<1 \% \mathrm{mf}$ prevalence in endemic populations can be attained to stop transmission. The focus of community participation is to have communities direct and manage the recruitment of volunteers and strategies for drug distribution. This is expected to help communities own the programs and bridge the gap between them and the health system..$^{35,61}$ When the process of community involvement does not function very well, myths and rumors about the program become rife and tend to hamper implementation. A number of MDAs in various countries have encountered the mistrust of the communities in the past. These include suspicions that the drugs are being used to poison children, being used as birth control and even causing erectile dysfunction. ${ }^{45,64}$ The fear of side effects and the lack of recognition of the benefit of adherence is also another challenge to participation among endemic populations..$^{51,65}$ Development of fever by asymptomatic mf carriers developed soon after consuming DEC led to a decline in participation in MDA among the population at risk. ${ }^{65}$ There is also a challenge of participation and compliance among populations, majority of whom do not show any visible signs of filarial infection..$^{53}$ This tends to happen in communities with low prevalence of the condition and a poor understanding of LF infection and transmission. ${ }^{66}$ This generally makes it difficult for MDA implementing teams to engage community members. Urban participation is more challenging due to transient populations in these areas, higher possibilities of absenteeism, low risk perception, insufficient information and communication among others. ${ }^{67}$

It is expected that social mobilization efforts could help engender more interest among community members. This can be done by getting traditional and religious leaders involved in these campaigns. Some work done showed that the volunteers worked with village chiefs and community health workers to devise strategies to help organize the social mobilization campaign. ${ }^{37}$ In most communities, CHVs are tasked with the responsibility of promoting the MDA in their communities. To ensure that communities participate fully in MDA programs, CHVs have to be adequately trained in order to gain public trust and ensure the program is not jeopardized. ${ }^{8}$ Adverse effects also tend to cause resistance among community members. Studies have reported dizziness, vomiting, itchiness, general weakness and other side effects being experienced by communities. ${ }^{66,68}$ This put undue fear in communities especially when there is inadequate counseling and social mobilization within the community. ${ }^{68}$ However, communities where awareness campaigns were planned showed persons agreeing to participate in order to avoid being infected. ${ }^{69}$ Testimonies from community members perceiving improved health could help eliminate this challenge.

\section{Conclusion}

MDA has become the choice mode of achieving the elimination goal of the GPELF; however, there are many challenges that hinder its successful implementation. Even though the LF elimination program has had a significant impact on not only LF elimination efforts but also on other helminth infections, there are challenges that need to be addressed. Strengthening of health systems and adopting an integrated approach to drug distribution is most likely to make MDA more effective. Data reporting should be made simpler and easier, especially at the community level so that more accurate data are given on MDA activities. CHVs can be incentivized both monetarily and non-monetarily to ensure that they give their best. Endemic communities should be involved from the planning to the implementation stages and this will ensure high and effective coverage. The LF elimination goal can be achieved, but this can only be done when issues pertaining to the drug distribution, the health system and implementation are addressed accordingly. In conclusion, since the inception of the GPELF, remarkable progress has been made. There is therefore the need to accelerate MDA strategies to reduce the time required to interrupt transmission in order to meet the 2020 target for elimination of LF as a public health problem.

\section{Disclosure}

The authors report no conflicts of interest in this work.

\section{References}

1. Centers for Disease Control and Prevention. Recommendations of the International Task Force for Disease Eradication. Morb Mortal Wkly Rep. 1993;42(RR-16):1-27.

2. Ichimori K, King JD, Engels D, et al. Global Programme to Eliminate Lymphatic Filariasis: the processes underlying programme success. PLoS Negl Trop Dis. 2014;8(12):e 3328.

3. World Health Organization. Progress report 2000-2009 and strategic plan 2010-2020 of the global programme to eliminate lymphatic filariasis: halfway towards eliminating lymphatic filariasis. Geneva: WHO;2010. . Available from: http://www.who.int/iris/handle/10665/44473. Accessed January 5, 2016.

4. Boyd A, Won KY, McClintock SK, et al. A community-based study of factors associated with continuing transmission of lymphatic filariasis in Leogane, Haiti. PLoS Negl Trop Dis. 2010;4(3):1-10.

5. Karam M, Ottesen E. The control of lymphatic filariasis. Med Trop (Mars). 2000;60(3):291-296. French. 
6. Gyapong JO, Kumaraswami V, Biswas G, Ottesen EA. Treatment strategies underpinning the global programme to eliminate lymphatic filariasis. Expert Opin Pharmacother. 2005;6(2):179-200.

7. World Health Organization. Preventive chemotherapy in human helminthiasis: coordinated use of antihelminthic drugs in control interventions: a manual for health professionals and programme managers. Geneva: WHO; 2006. Available from: http://www.who.int/iris/ handle/10665/43545. Accessed February 1, 2017.

8. World Health Organization. Provisional strategy for interrupting lymphatic filariasis transmission in loiasis-endemic countries: report of the meeting on lymphatic filariasis, malaria and integrated veector management. 2012.

9. WHO. Weekly Epidemiological Record. 2016;91(39):441-460.

10. World Health Organization. Lymphatic filariasis.: Fourth report of the WHO Expert Committee on Filariasis. World Health Organ Tech Rep Ser. 1984;702:3-112.

11. Ottesen EA. Efficacy of diethylcarbamazine in eradicating infection with lymphatic-dwelling filariae in humans. Rev Infect Dis. 1985;7(3):341-356.

12. Ottesen EA, Ismail MM, Horton J. The role of albendazole in programmes to eliminate lymphatic filariasis. Parasitol Today. 1997;15(9):382-386.

13. Ottesen EA, Hooper PJ, Bradley M, Biswas G. The global programme to eliminate lymphatic filariasis: health impact after 8 years. In: The Causes and Impacts of Neglected Tropical and Zoonotic Diseases: Opportunities for Integrated Intervention Strategies. Washington, DC: National Academies Press; 2011.

14. Horton J, Witt C, Ottesen EA, et al. An analysis of the safety of the single dose, two drug regimens used in programmes to eliminate lymphatic filariasis. Parasitology. 2000;121 Suppl:S147-S160.

15. Shenoy RK, Suma TK, John A, et al. The pharmacokinetics, safety and tolerability of the co-administration of diethylcarbamazine and albendazole. Ann Trop Med Parasitol. 2002;96(6):603-614.

16. Ismail MM, Jayakody RL, Weil GJ, et al. Efficacy of single dose combinations of albendazole, ivermectin and diethylcarbamazine for the treatment of bancroftian filariasis. Trans $R$ Soc Trop Med Hyg. 1998;92(1):94-97.

17. Ottesen EA. The Global Programme to Eliminate Lymphatic Filariasis. Trop Med Int Heal. 2000;5(9):591-594.

18. Hussain MA, Sitha AK, Swain S, Kadam S, Pati S. Mass drug administration for lymphatic filariasis elimination in a coastal state of India: a study on barriers to coverage and compliance. Infect Dis Poverty. 2014;3(1):31.

19. Jambulingam P, Subramanian S, de Vlas SJ, Vinubala C, Stolk WA. Mathematical modelling of lymphatic filariasis elimination programmes in India: required duration of mass drug administration and posttreatment level of infection indicators. Parasit Vectors. 2016;9(1):501.

20. De-Jian S, Xu-Li D, Ji-Hui D. The history of the elimination of lymphatic filariasis in China. Infect Dis Poverty. 2013;2(1):30.

21. Sudomo M, Chayabejara S, Duong S, Hernandez L, Wu WP, Bergquist R. Elimination of lymphatic filariasis in Southeast Asia. Adv Parasitol. 2010;72:205-233.

22. Hoerauf A, Mand S, Fischer K, et al. Doxycycline as a novel strategy against bancroftian filariasis-depletion of Wolbachia endosymbionts from Wuchereria bancrofti and stop of microfilaria production. Med Microbiol Immunol. 2003;192(4):211-216.

23. Ramaiah KD, Ottesen EA. Progress and impact of 13 years of the global programme to eliminate lymphatic filariasis on reducing the burden of filarial disease. PLoS Negl Trop Dis. 2014;8(11):e3319.

24. Weil GJ, Kastens W, Susapu M, et al. The impact of repeated rounds of mass drug-administration with diethylcarbamazine plus albendazole on bancroftian filariasis in Papua New Guinea. PLoS Negl Trop Dis. 2008;2(12):e344.

25. Supali T, Djuardi Y, Bradley M, Noordin R, Rückert P, Fischer PU. Impact of six rounds of mass drug administration on Brugian filariasis and soil-transmitted helminth infections in Eastern Indonesia. PLoS Negl Trop Dis. 2013;7(12):1-9.
26. Liang JL, King JD, Ichimori K, Handzel T, Pa'au M, Lammie PJ. Impact of five annual rounds of mass drug administration with diethylcarbamazine and albendazole on Wuchereria bancrofti infection in American Samoa. Am J Trop Med Hyg. 2008;78(6):924-928.

27. Swaminathan S, Perumal V, Adinarayanan S, Kaliannagounder K, Rengachari R, Purushothaman J. Epidemiological assessment of eight rounds of mass drug administration for lymphatic filariasis in India: implications for monitoring and evaluation. PLoS Negl Trop Dis. 2012;6(11):e1926.

28. Mupfasoni D, Montresor A, Mikhailov A, King J. The impact of lymphatic filariasis mass drug administration scaling down on soiltransmitted helminth control in school-age children. Present situation and expected impact from 2016 to 2020. PLoS Negl Trop Dis. 2016;10(12):e0005202.

29. Oqueka T, Supali T, Ismid IS, et al. Impact of two rounds of mass drug administration using diethylcarbamazine combined with albendazole on the prevalence of Brugia timori and of intestinal helminths on Alor Island, Indonesia. Filaria J. 2005;4:5.

30. Mensah EO, Aikins MK, Gyapong M, Anto F, Bockarie MJ, Gyapong JO. Extent of integration of priority interventions into general health systems: a case study of neglected tropical diseases programme in the Western region of Ghana. PLoS Negl Trop Dis. 2016;10(5):1-16.

31. Omedo MO, Matey EJ, Awiti A, et al. Community health workers' experiences and perspectives on mass drug administration for schistosomiasis control in Western Kenya: the SCORE project. Am J Trop Med Hyg. 2012;87(6):1065-1072.

32. Odhiambo GO, Musuva RM, Odiere MR, Mwinzi PN. Experiences and perspectives of community health workers from implementing treatment for schistosomiasis using the community directed intervention strategy in an informal settlement in Kisumu City, western Kenya. BMC Public Health. 2016;16(1):986.

33. Abd Elaziz KM, El-Setouhy M, Bradley MH, Ramzy RM, Weil GJ. Knowledge and practice related to compliance with mass drug administration during the Egyptian national filariasis elimination program. Am J Trop Med Hyg. 2013;89(2):260-264.

34. Fleming FM, Matovu F, Hansen KS, Webster JP. A mixed methods approach to evaluating community drug distributor performance in the control of neglected tropical diseases. Parasit Vectors. 2016; $9(1): 345$.

35. Gyapong JO, Gyapong M, Yellu N, et al. Integration of control of neglected tropical diseases into health-care systems: challenges and opportunities. Lancet. 2010;375(9709):160-165.

36. Krentel A, Fischer PU, Weil GJ. A review of factors that influence individual compliance with mass drug administration for elimination of lymphatic filariasis. PLoS Negl Trop Dis. 2013;7(11):e2447.

37. Dembélé M, Bamani S, Dembélé R, et al. Implementing preventive chemotherapy through an integrated national neglected tropical disease control program in Mali. PLoS Negl Trop Dis. 2012;6(3):e1574.

38. Marchal B, Van Dormael M, Pirard M, Cavalli A, Kegels G, Polman K. Neglected tropical disease (NTD) control in health systems: the interface between programmes and general health services. Acta Trop. 2011;120(Suppl 1):S177-S185.

39. Coulibaly YI, Dicko I, Keita M, et al. A cluster randomized study of the safety of integrated treatment of trachoma and lymphatic filariasis in children and adults in Sikasso, Mali. PLoS Negl Trop Dis. 2013;7(5):e2221.

40. Savigny D de, Adam T. Systems thinking for health systems strengthening. Alliance Heal Policy Syst Res WHO. 2009;7:1-112.

41. Macpherson EE, Adams ER, Bockarie MJ, et al. Mass Drug Administration and beyond: how can we strengthen health systems to deliver complex interventions to eliminate neglected tropical diseases? BMC Proc. 2015;9(Suppl 10):S7.

42. Cavalli A, Bamba SI, Traore MN, et al. Interactions between global health initiatives and country health systems: the case of neglected tropical diseases control programme in Mali. PLoS Negl Trop Dis. 2010;4(8):e798 
43. Goldman AS, Guisinger VH, Aikins M, et al. National mass drug administration costs for lymphatic filariasis elimination. PLoS Negl Trop Dis. 2007;1(1):e67.

44. da-Costa Vroom FB, Aryeetey R, Boateng R, et al. Data reporting constraints for the lymphatic filariasis mass drug administration activities in two districts in Ghana: a qualitative study. SAGE Open Med. 2015;3:2050312115594083.

45. Allen T, Parker M. Will increased funding for neglected tropical diseases really make poverty history? Lancet. 2012;379(9821):1097-1098.

46. Nonvignon J, Mensah E, da-CostaVroom FB, Adjei S, Gyapong JO. The role of health systems in the control of neglected tropical diseases in SubSaharan Africa. In: Gyapong JO, Boatin B, editors. Neglected Tropical Diseases-Sub-Saharan Africa. Switzerland: Springer; 2016:385-405.

47. Baker MC, Krotki K, Sankara DP, et al. Measuring treatment coverage for neglected tropical disease control programs: analysis of a survey design. Am J Epidemiol. 2013;178(2):268-275.

48. Heunis C, Wouters E, Kigozi G, et al. Accuracy of tuberculosis routine data and nurses' views of the TB-HIV information system in the Free State, South Africa. J Assoc Nurses AIDS Care. 2011;22(1):67-73.

49. Mavimbe JC, Braa J, Bjune G. Assessing immunization data quality from routine reports in Mozambique. BMC Public Health. 2005;5:108.

50. de Souza DK, Yirenkyi E, Otchere J, et al. Assessing lymphatic filariasis data quality in endemic communities in Ghana, using the neglected tropical diseases data quality assessment tool for preventive chemotherapy. PLoS Negl Trop Dis. 2016;10(3):1-12.

51. Cantey PT, Rout J, Rao G, Williamson J, Fox LM. Increasing compliance with mass drug administration programs for lymphatic filariasis in India through education and lymphedema management programs. PLoS Negl Trop Dis. 2010;4(6):1-8.

52. Lahariya C, Mishra A. Strengthening of mass drug administration implementation is required to eliminate lymphatic filariasis from India: an evaluation study. J Vector Borne Dis. 2008;45(4):313-320.

53. Bhullar N, Maikere J. Challenges in mass drug administration for treating lymphatic filariasis in Papua, Indonesia. Parasit Vectors. 2010;3:70.

54. Worrell C, Mathieu E. Drug coverage surveys for neglected tropical diseases: 10 Years of field experience. Am J Trop Med Hyg. 2012;87(2):216-222.

55. Mathauer I, Imhoff I. Health worker motivation in Africa: the role of non-financial incentives and human resource management tools. Hum Resour Health. 2006;4:24.

56. Greenspan JA, McMahon SA, Chebet JJ, et al. Sources of community health worker motivation: a qualitative study in Morogoro Region, Tanzania. Hum Resour Health. 2013;11(1):52.

57. Bhattacharyya K, Winch P, LeBan K, Tien M. Community health worker incentives and disincentives: how they affect motivation, retention, and sustainability. Arlington, VA:Basic Support Institutionalizing Child Surviv Proj (BASICS II); 2001:1-52.
58. Amazigo UV, Leak SG, Zoure HG, Njepuome N, Lusamba-Dikassa PS. Community-driven interventions can revolutionise control of neglected tropical diseases. Trends Parasitol. 2012;28(6):231-238.

59. Takasugi T, Lee AC. Why do community health workers volunteer? A qualitative study in Kenya. Public Health. 2012;126(10): 839-845.

60. Emukah EC, Enyinnaya U, Olaniran NS, et al. Factors affecting the attrition of community-directed distributors of ivermectin, in an onchocerciasis-control programme in the Imo and Abia states of southeastern Nigeria. Ann Trop Med Parasitol. 2008;102(1):45-52.

61. Gyapong J, Gyapong M, Owusu-Banahene G, Wamae N, Njenga SM, Mukoko DN. Community-directed treatment of lymphatic filariasis in Africa: report of a multi-centre study in Ghana and Kenya. Geneva: UNDP/World Bank/WHO Special Programme for Research \& Training in Tropical Disease (TDR); 2000.

62. Njomo DW, Amuyunzu-Nyamongo M, Magambo JK, Ngure PK, Njenga SM. Factors associated with the motivation of community drug distributors in the Lymphatic Filariasis Elimination Programme in Kenya. South Afr J Epidemiol Infect. 2012;27(2):66-70.

63. Lehmann U, Sanders D. Community health workers: what do we know about them? The state of the evidence on programmes, activities, costs and impact on health outcomes of using community health workers. Geneva: WHO; 2007.

64. Sodahlon YK, Dorkenoo AM, Morgah K, et al. A success story: Togo is moving toward becoming the first sub-Saharan African nation to eliminate lymphatic filariasis through mass drug administration and countrywide morbidity alleviation. PLoS Negl Trop Dis. 2013;7(4): e2080.

65. Kumar A, Sachan P. Measuring impact on filarial infection status in a community study: role of coverage of mass drug administration (MDA). Trop Biomed. 2014;31(2):225-229.

66. Wynd S, Carron J, Selve B, Leggat PA, Melrose W, Durrheim DN. Qualitative analysis of the impact of a lymphatic filariasis elimination programme using mass drug administration on Misima Island, Papua New Guinea. Filaria J. 2007;6:1.

67. Njomo DW, Mukoko DA, Nyamongo NK, Karanja J. Increasing coverage in mass drug administration for lymphatic filariasis elimination in an urban setting: a study of Malindi town, Kenya. PLoS One. 2014;9(1):e83413.

68. Karmakar PR, Mitra K, Chatterjee A, Jana PK, Bhattacharya S, Lahiri SK. A study on coverage, compliance and awareness about mass drug administration for elimination of lymphatic filariasis in a district of west Bengal, India. J Vector Borne Dis. 2011;48(2):101-104.

69. King JD, Zielinski-Gutierrez E, Pa'au M, Lammie P. Improving community participation to eliminate lymphatic filariasis in American Samoa. Acta Trop. 2011;120(Suppl 1):48-54.
Research and Reports in Tropical Medicine

\section{Publish your work in this journal}

Research and Reports in Tropical Medicine is an international, peerreviewed, open access journal publishing original research, case reports, editorials, reviews and commentaries on all areas of tropical medicine, including: Diseases and medicine in tropical regions; Entomology; Epidemiology; Health economics issues; Infectious disease; Laboratory science and new technology in tropical medicine; Parasitology; Public health medicine/health care policy in tropical regions; and Microbiology. The manuscript management system is completely online and includes a very quick and fair peer-review system. Visit http://www.dovepress. com/testimonials.php to read real quotes from published authors. 